\title{
PENGARUH METODE COOPERATIVE LEARNING TEKNIK JIGSAW TERHADAP PRESTASI BELAJAR MAHASISWA
}

\author{
(Survei pada Mahasiswa Program Tata Niaga 2006, Jurusan Pendidikan Ekonomi FPIPS UPI \\ Bandung pada Mata Kuliah Manajememen Operasi)
}

\author{
Lili Adi Wibowo ${ }^{1}$
}

\begin{abstract}
Abstrak : Penelitian ini bertujuan untuk mengetahui gambaran Metode Cooperative Learning Teknik Jigsaw dan pengaruhnya terhadap Prestasi Belajar Mahasiswa Program Tata Niaga 2006 Jurusan Pendidikan Ekonomi FPIPS UPI Bandung pada Mata Kuliah Manajemen Operasi. Penelitian ini bersifat deskriptif verifikatif dan menggunakan metode explanatory survey, selain itu berdasarkan kurun waktu, penelitiannya menggunakan metode pengembangan cross sectional methode. Data yang disajikan adalah data primer dan data sekunder yang dikumpulkan melalui observasi, studi kepustakaan, dan angket.Adapun teknik analisa yang digunakan adalah analisis regresi dengan alat bantu software komputer SPSS 12. Berdasarkan hasil pengujian statistik diperoleh temuan terdapat pengaruh yang positif antara Metode Cooperative Learning Teknik Jigsaw dengan Prestasi Belajar. Maka diperoleh kesimpulan bahwa Prestasi Belajar dipengaruhi oleh Metode Cooperative Learning Teknik Jigsaw.
\end{abstract}

\begin{abstract}
This study is aimed to know the description of Cooperative Learning Methods Jigsaw Techniques and its influence on Student Learning Achievement of the student in Economic Education Program 2006, Faculty of Social Sciences Universitas Pendidikan Indonesia, Bandung. This study is a descriptive verification study with explanatory survey method and cross sectional method based on time period. The data are presented in primary and secondary data with the data collectted through observation, library research, and questionnaire. The analysis technique is regression analysis with SPSS computer software as the tool 12. Based on the findings obtained by statistical tests shows that there is a positive influence of Cooperative Learning Methods Jigsaw Techniques with students' Learning Achievement. It can be concluded that achievement is influenced by the Method of Cooperative Learning Jigsaw Technique.
\end{abstract}

Kata Kunci : Cooperatif learning teknik Jigsaw, prestasi belajar.

\section{PENDAHULUAN}

Manusia dikatakan sebagai makhluk yang memiliki multiple intelegency (kecerdasan multi) dari mulai intelegency quotion (IQ), emotional quotion (EQ) sampai Spritual quotion (SQ). Berdasarkan potensi yang sangat besar tersebut, manusia memiliki kemampuan untuk mempelajari berbagai hal. Masalah yang terjadi adalah potensi tersebut tidak selalu digali dan diolah dengan maksimal.

Dunia pendidikan pada dasarnya terbagi atas tiga, yaitu pendidikan formal, informal, dan non formal. Ketiga jenis pendidikan tersebut memiliki peranan yang sama pentingnya untuk membentuk karakter sumber daya manusia. Dalam dunia pendidikan formal, prestasi belajar ini dipengaruhi oleh berbagai hal diantaranya Guru, peraturan, sarana prasarana dan metode. Komponen ini saling berkaitan satu dengan yang lainnya dan mempengaruhi prestasi belajar siswa.

Kecenderungan metode belajar yang terjadi didunia pendidikan adalah menggunakan metode ceramah, dimana guru hanya mentransfer ilmunya ke murid di dalam kelas melalui komunikasi satu arah. Terpaku pada metode ceramah mengakibatkan potensi yang ada dalam diri sesorang tidak muncul dan berkembang. Itulah sebabnya pendidikan harus selalu berusaha menerapkan metode dimana peserta didik dapat ikut berpartisipasi lebih aktif 
dalam proses belajar dan mencapai hasil belajar yang maksimal. Salah satu metode tersebut adalah metode cooperative learning (metode pembelajaran gotog royong). Nama metode ini sebenarnya sangat berkaitan dengan nilai yang dimiliki oleh bangsa Indonesia yaitu nilai gotong royong. Namun sangat disayangkan karena sekalipun Indonesia memiliki nilai tersebut, metode cooperative learning belum banyak dikembangkan dalam kegiatan belajarmengajar.

Berdasarkan beberapa teknik yang dikembangkan dalam metode cooperative learning tersebut, ada satu teknik yang sangat menarik perhatian penulis yaitu teknik jigsaw.

Menurut Anita Lie (2004:69) teknik ini mengembangkan kegiatan membaca, menulis, dan berbicara. Pendekatan ini bisa pula digunakan dalam beberapa mata pelajaran seperti ilmu pengetahuan alam, ilmu pengetahuan sosial, matematika, agama, dan bahasa. Teknik ini juga cocok untuk semua kelas atau tingkatan. Jigsaw merupakan salah satu teknik yang digunakan dalam metode cooperative learning

\section{IDENTIFIKASI MASALAH}

Dalam rangka meneliti pengaruh metode (metode pembelajaran gotong royong) terhadap prestasi belajar, maka diidentifikasikan masalah penelitian yang diidenifikasikan sebagai berikut:

1. Bagaimana gambaran metode cooperative learning teknik Jigsaw

2. Bagaimana gambaran prestasi belajar yang diraih oleh mahasiswa angkatan 2006 program Tata Niaga UPI pada mata kuliah Manajemen Operasi.

3. Bagaimana pengaruh metode cooperative learning teknik Jigsaw terhadap prestasi belajar mahasiswa angkatan 2006 program Tata Niaga UPI pada mata kuliah Manajemen Operasi.

\section{TUJUAN PENELITIAN}

Tujuan dari penelitian ini adalah sebagai erikut:
1 Untuk mengetahui gambaran metode cooperative learning teknik Jigsaw

2 Untuk mengetahui gambaran prestasi belajar yang diraih oleh mahasiswa angkatan 2006 program Tata Niaga UPI pada mata kuliah Manajemen Operasi.

3 Untuk mengetahui pengaruh metode cooperative learning teknik Jigsaw terhadap prestasi belajar mahasiswa angkatan 2006 program Tata Niaga UPI pada mata kuliah Manajemen Operasi

\section{KEGUNAAN PENELITIAN}

Kegunaan yang diharapkan peneliti melalui penelitian ini adalah :

\section{Kegunaan Akademis}

Hasil penelitian dari makalah ini diharapkan dapat dijadikan salah satu bahan untuk meningkatkan wawasan dan ilmu pengetahuan mengenai pengaruh metode cooperative learning teknik Jigsaw terhadap prestasi belajar.

2. Kegunaan Praktis

Hasil penelitian ini diharapkan dapat dijadikan bahan pertimbangan bagi pengajar khususnya dalam pelaksanaan metode cooperative learning teknik jigsaw, serta upaya-upaya apa yang harus dilakukan untuk meningkatkan dan mempertahankan prestasi belajar mahasiswa

\section{LANDASAN TEORI}

Teknik Jigsaw pertama kali dikembangkan pada tahun 1971 di Austin, Texas. Teknik ini digunakan oleh Elliot Aronson dan murid-muridnya. Jigsaw merupakan salah satu teknik dalam metode cooperative learning dimana siswa tergabung dalam kelompok-kelompok kecil untuk membahas bersama materi berbeda yang diberikan kepada siswa dalam kelompok.

Elliot Aronson (2000) memberikan pengertian tentang jigsaw "The jigsaw classroom is a cooperative learning technique with a three-decade track record of successfully reducing racial conflict and increasing positive educational outcomes. " 
Selain itu, Elliot Aronsosn (2000) menjelaskan juga kelebihan dari teknik jigsaw yaitu:

1. Kebanyakan guru menemukan bahwa penerapan teknik jigsaw dalam kegiatan belajar mengajar adalah mudah.

2. Kebanyakan guru sangat menikmati penerapan teknik jigsaw dalam kegiatan belajar mengajar.

3. Teknik jigsaw dapat digunakan bersama strategi belajar mengajar yang lain.

4. Teknik jigsaw tetap dapat diterapkan sekalipun hanya satu jam per hari.

5. Penerapan teknik jigsaw tidak mengeluarkan biaya apapun.

Pada pelaksanaan atau penerapan teknik jigsaw, ada beberapa prosedur yang harus dipahami oleh guru. Prosedur pelaksanaan teknik jigsaw tersebut ialah sebagai berikut:

1. Membentuk kelompok

Siswa dibentuk dalam kelompok, dimana setiap kelompok terdiri dari 5-6 orang yang memiliki perbedaan dalam hal : kemampuan, suku bangsa maupun jenis kelamin, kemudian setiap kelompok menentukan satu orang sebagai ketua dalam kelompoknya masing-masing.

(Apabila setiap siswa diberi simbol angka maka bentuk setiap kelompok adalah: 1-2-3-4-5-6; 1-2-3-4-5-6; 1-2-3$4-5-6 ; 1-2-3-4-5-6 ; 1-2-3-4-5-6)$

2. Pembagian tugas

Setiap siswa dalam satu kelompok diberikan tugas yang berbeda-beda. Apabila ada enam siswa dalam satu kelompok maka ada enam potongan materi berbeda yang diberikan.

(Apabila potongan materi diberikan simbol huruf maka bentuk pembagian tugas adalah: 1-A,2-B,3-C,4-D,5-E,6-F; 1-A,2-B,3-C,4-D,5-E,6-F; 1-A,2-B,3C,4-D,5-E,6-F; 1-A,2-B,3-C,4-D,5-E,6-F; 1-A,2-B,3-C,4-D,5-E,6-F)

3. Pemahaman materi

Setiap kelompok diberikan waktu untuk memahami materi yang telah diberikan dan guru perlu memperhatikan kondisi agar tetap tertib. Setiap siswa bertanggung jawab untuk memahami potongan materi yang dimiliki, kemudian tiap anggota kelompok menyampaikan informasi yang telah diperoleh kepada rekan kelompoknya.

4. Kelompok ahli

Setelah itu, setiap siswa yang memiliki potongan materi yang sama akan bergabung dalam suatu kelompok yang disebut sebagai kelompok ahli dan didalam kelompok tersebut setiap siswa membagikan apa yang dipahaminya mengenai materi tersebut.

(Bentuk kelompok ahli:1-1-1-1-1; 22-2-2-2; 3-3-3-3-3; 4-4-4-4-4: 5-5-5-5-5: 6-6-6-6-6)

5. Kembali kepada kelompok awal

Setiap siswa yang telah memperoleh informasi dalam kelompok ahli bertanggung jawab untuk membagikannya kepada rekan kelompoknya. Setiap siswa mempunyai tanggung jawab untuk melakukannya.

(kelompok kembali dalam bentuk semula: 1-2-3-4-5-6; 1-2-3-4-5-6; 1-2-3$4-5-6 ; 1-2-3-4-5-6 ; 1-2-3-4-5-6)$

6. Kuis

Pada akhirnya, guru memberikan kuis kepada siswa dimana soal kuis tersebut berkaitan dengan keseluruhan materi yang diberikan, dan hasil kuis setiap siswa akan dihitung. Hal ini dilakukan agar siswa tidak menganggap penggunaan teknik ini hanya sekedar permainan saja.

Setelah siswa selesai menggunakan metode cooperative learning teknik jigsaw, maka diberikan reward bagi siswa dan kelompok yang memperoleh nilai tinggi. Cara yang digunakan dalam penentuan nilai kelompok adalah menghitung nilai rata-rata kelompok.

Penerapan teknik jigsaw dapat membantu siswa menyampaikan informasi belajar terhadap siswa lainnya. Siswa diharapkan berpikir secara kritis dalam memahami materi pelajaran agar mampu menyampaikan seluruh informasi dengan tepat kepada rekan sebayanya. Hal ini secara tidak langsung mengajarkan siswa untuk dapat berpikir secara kritis, mampu 
berkomunikasi dan bersosialisasi dengan temannya. Penerapan teknik jigsaw juga dapat menumbuhkan motivasi belajar siswa, dapat belajar memahami karakter orang lain melalui kelompok jigsaw dan kelompok ahli. Selain itu juga, penerapan teknik jigsaw dapat melatih siswa untuk bertanggung jawab dengan tugas yang diberikan. Tugas yang diberikan bersifat terstruktur artinya pada saat siswa melakukan proses belajar bersama rekan sebayanya (peer teaching) siswa perlu bertukar informasi secara sistematis dan menyatukan materi utuh, karena setiap siswa memiliki potongan materi yang berbeda. Cara berpikir kritis dan sistematis merupakan proses berpikir ilmiah. Terkait dengan berpikir ilmiah yang diterapkan dalam metode cooperative learning teknik jigsaw dapat membantu tercapainya salah satu tujuan dalam strategi belajar mengajar.

\section{HIPOTESIS}

Sebelum mengemukakan hipotesisnya, terlebih dahulu penulis jelaskan pengertian hipotesis menurut Sugiyono (2002:38) sebagai berikut : "Hipotesis dapat diartikan sebagai jawaban yang bersifat sementara terhadap permasalahan penelitian sampai terbukti melealui data yang terkumpul."

Berdasarkan pendapat di atas, maka dapat disimpulkan bahwa hipotesis merupakan jawaban sementara yang belum final (akhir) dan masih harus dibuktikan kebenarannya melalui penelitian lebih lanjut.

Secara umum metode cooperative learning teknik jigsaw memberi pengaruh positif terhadap prestasi belajar. Dengan demikian, maka dalam penelitian ini penulis mengemukakan hipotesis bahwa : "prestasi belajar dipengaruhi secara positif oleh pelaksanaan metode cooperative learning teknik jigsaw.

\section{METODOLOGI PENELITIAN}

Jenis penelitian yang digunakan dalam penelitian ini, yaitu penelitian deskriptif dan verifikatif yang dilaksanakan melalui pengumpulan data di lapangan, maka metode penelitian yang digunakan adalah metode deskriptif survey dan metode explanatory survey.

Metode deskriftip survey dan explanatory survey merupakan metoda peneleitian yang dilakukan pada populasi besar maupun kecil, tetapi data yang dipelajari adalah data dari sampel yang diambil dari populasi tersebut, sehingga ditemukan deskripsi dan hubungan-hubungan antar varaibel. Dalam penelitian yang menggunakan metode ini informasi dari sebagian populasi dikumpulkan langsung ditempat kejadian secara empirik dengan tujuan untuk mengetahui pendapat dari sebagian populasi terhadap objek yang sedang diteliti. Adapun penelitian ini dilakukan dalam jangka waktu kurang dari satu tahun, oleh karena itu metode pengembangan yang digunakan adalah crosssectional yaitu metode penelitian dengan cara mempelajari obyek dalam satu kurun waktu tertentu (tidak berkesinambungan dalam jangka waktu panjang.

Yang menjadi populasi dalam penelitian adalah mahasiswa program Tata Niaga angkatan 2006 FPIPS UPI yang telah mengikuti mata kuliah manajemen operasi.

Pengujian hipotesis dilakukan dengan menggunakan analisis regresi linear sederhana. Alat penelitian yang digunakan dalam penelitian ini adalah angket. Angket ini disusun oleh penulis berdasarkan variable yang terdapat dalam penelitian, yaitu memberikan keterangan dan data mengenai pengaruh metode cooperatif learning terhadap prestasi belajar siswalokasi. Tabel 1 di bawah ini menyajikan data operasionalisasi variabel penelitian 
TABEL 1

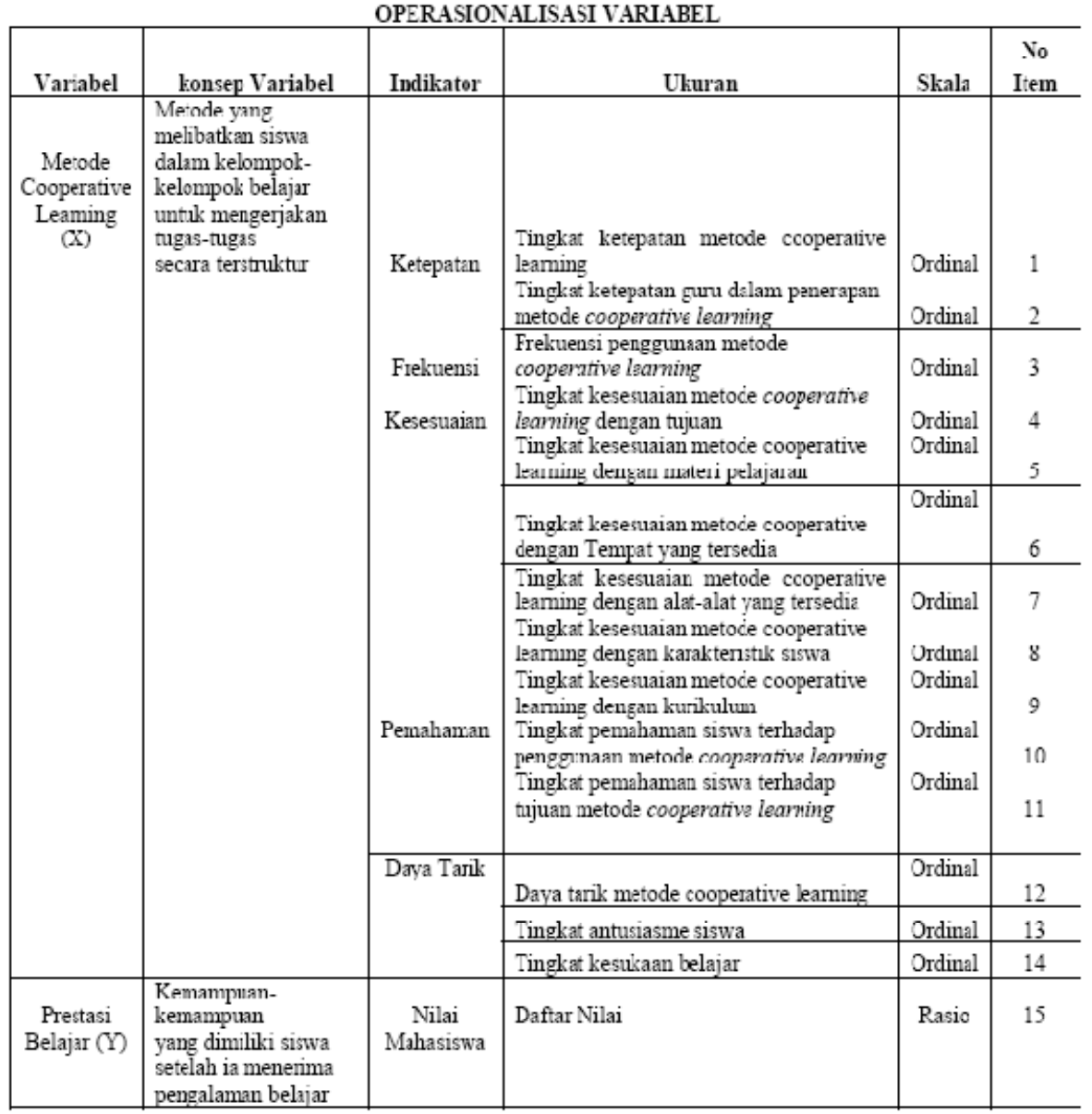

\section{HASIL PENELITIAN DAN PEMBAHASAN}

Hasil penelitian dan pembahasan akan disajikan secara terurut. Dimulai dengan rekapitulasi tanggapan responden terhadap variabel penelitian, kemudian pengujian dan pembahasan hipotesis, dan diakhiri dengan penyajian mengenai implikasi penelitian ini terhadap bidang kajian yang diteliti.

\section{REKAPITULASI TANGGAPAN RESPON-DEN TERHADAP VARIABEL PENELITIAN}

\section{Gambaran Cooperative Teknik Jigsaw}

Secara keseluruhan

Learning

variabel cooperative learning Teknik jigsaw dapat diketahui kedudukannya berdasarkan skor yang telah diperoleh dimana nilai-nilai tersebut dibandingkan dengan kriteria skor standar, yang diperoleh melalui perhitungan skor ideal (kriterium) dan skor terkecil, sehingga melalui skor standar tersebut dapat diketahui daerah kontinum yang menunjukkan wilayah ideal dari sub variabel ketepatan, frekuensi, kesesuaian, pemahaman dan daya tarik hal tersebut dapat dicari dengan rumus Sugiyono (2002:94) sebagai berikut:

Mencari Skor Ideal Metode Cooperative Learning Teknik Jigsaw

Skor Ideal $=$ Skor Tertinggi $\mathrm{x}$ Jumlah Butir Item $x$ Jumlah responden

Skor Ideal $=5 \times 14 \times 72=5040$

Mencari Skor Terendah Metode Cooperative

Learning Teknik Jigsaw

Skor Terendah $=$ Skor Terendah $\mathrm{x}$ Jumlah Butir Item x Jumlah responden Skor Terendah $=1 \times 14 \times 72=1008$ 
Mencari Panjang Interval Kelas Metode Cooperative Learning Teknik Jigsaw

Panjang Interval Kelas $=$ Skor Ideal : Banyak Kelas Interval

Panjang Interval Kelas $=5040: 5=1008$
Berdasarkan penelitian dengan menyebarkan angket kepada 72 responden dapat diketahui gambaran mengenai variabel metode cooperative learning teknik jigsaw (X) yang paling dominan dapat dilihat dalam tabel 2

Tabel 2

Rekapitulasi Skor Tanggapan Responden Mengenai Indikatcr Cooperative Learning Teknik Jigsaw

\begin{tabular}{|c|c|c|c|c|}
\hline No & Indikator & Sko: & $\begin{array}{l}\text { Skor } \\
\text { Ideal }\end{array}$ & $\%$ \\
\hline \multicolumn{5}{|c|}{ Ketepatan } \\
\hline 1 & $\begin{array}{l}\text { Tingkat ketepatan metode cooperative learning } \\
\text { Tingkat ketepatan guru dalam penerapan metode cooperative }\end{array}$ & 317 & 360 & 83.06 \\
\hline 2 & leaming & 311 & 360 & 85.39 \\
\hline & Total Skor Kotopatan & 628 & 720 & 87.22 \\
\hline \multicolumn{5}{|c|}{ Frekuensi } \\
\hline 3 & Frekuensi pengzunaan metode cooperative learning & 308 & 360 & 85.56 \\
\hline \multicolumn{5}{|c|}{ Kesesuaian } \\
\hline 4 & Tingkat kesesuaian metode cooperative learming dengan trjuan & 297 & 360 & 82.50 \\
\hline 5 & $\begin{array}{l}\text { Tingkat kesesuaian metode cooperative leaming dengan materi } \\
\text { pelajaran }\end{array}$ & 300 & 360 & 83.33 \\
\hline 6 & $\begin{array}{l}\text { Tingkat kesesuaian metode cooperative dengan tempat yaug } \\
\text { tersediz }\end{array}$ & 284 & 360 & 73.89 \\
\hline 7 & $\begin{array}{l}\text { Tingkat kesesurian metode cooperative leaming dengan } \\
\text { alat-alat yang tersedia }\end{array}$ & 284 & 360 & 73.89 \\
\hline $\begin{array}{l}8 \\
9\end{array}$ & $\begin{array}{l}\text { Tingkat kesesuaian metode cooprative leaming dengan } \\
\text { karakteristik siswa } \\
\text { Tingkat kesesuaian metode cooperative leaming dengan } \\
\text { kurikuhm }\end{array}$ & 278 & $\begin{array}{l}360 \\
360\end{array}$ & 87.22 \\
\hline & Total Skor Kesesuaian & 1734 & 2160 & 90.28 \\
\hline \multicolumn{5}{|c|}{ Pemahaman } \\
\hline 10 & $\begin{array}{l}\text { Tinglat pemahaman ciswa torhadap pongzumaan motodo } \\
\text { cooperative leaming }\end{array}$ & 290 & $0^{36}$ & 80.56 \\
\hline 11 & $\begin{array}{l}\text { Tingkat pemahaman siswa terhadap tujuan metode cooperative } \\
\text { learning }\end{array}$ & 289 & 360 & 89.28 \\
\hline & Total Skor Penahamaz & 579 & 720 & 89.42 \\
\hline \multicolumn{5}{|c|}{ Daya Tarik } \\
\hline 12 & Daya tarik metode cooperative leaming & 286 & 360 & 79.44 \\
\hline 13 & Tingkat antusiasme siswa & 292 & 360 & 81.11 \\
\hline 14 & Tingkat kesukaan belajar & 288 & 360 & 89.00 \\
\hline & Total Skor Dara Tarik & 866 & 1080 & 90.19 \\
\hline & Total Skor Metode Cooperative Learning Tekrik Jigsaw & 4115 & $\mathbf{5 0 4 0}$ & 81.65 \\
\hline
\end{tabular}


Berdasarkan Tabel 2 diatas mengenai gambaran metode cooperative learning teknik jigsaw secara keseluruhan dinilai tepat yaitu sebesar 81,65 dan secara berurutan dapat diketahui indikator-indikator atribut yang dominan. Indikator yang paling dominan adalah ketepatan yakni ketepatan cooperative learning teknik jigsaw dalam proses belajar mengajar yaitu $88,06 \%$ indikator tertinggi kedua adalah indikator ketepatan guru dalam penerapan metode cooperative learning teknik jigsaw 86,39\% dan yang paling rendah adalah Penggunaan metode cooperative learning terhadap karakteristik siswa sebesar $72,22 \%$.

Responden berpendapat bahwa yang paling dominan adalah ketepatan cooperative learning teknik jigsaw dalam proses belajar mengajar karena dalam metode ini setiap siswa belajar bersama teman sebaya, dan mengerjakan tugas-tugas secara bersama sehingga ide yang diperoleh tidak hanya dari satu orang tetapi dari berbagai orang. Hal ini sesuai dengan pendapat Roger dan David Johnson (1996), mengemukakan bahwa: dasar yang digunakan dalam metode cooperative learning yang dikutip dari Ecclesiattics 4:9-12 adalah: Berdua lebih baik daripada seorang diri karena mereka menerima upah yang baik dalam jerih payah mereka. Karena kalau mereka jatuh, yang seorang mengangkat temannya. Selain itu Jones (Irma Mariawati Nusa'adah, 2003) juga menyatakan kelebihan dari metode cooperative learning adalah: Siswa belajar dari temannya, mempelajari materi secara mendalam dan siswa telah menyenanginya dengan adanya interaksi antara siswa dengan teman kelompoknya, siswa belajar mengenai nilai-nilai sosial seperti memutuskan suatu keputusan, problem solving, mengkritisi ideide, bertanya, memberikan petunjuk bagaimana mengerjakan tugas dan membangun bersama informasi yang terpisah menjadi satu, siswa menikmati suasana kerja sama karena mereka dengan aktif terlibat langsung dalam proses pembelajaran.

\section{Gambaran Prestasi Belajar}

Secara keseluruhan variabel prestasi belajar dapat diketahui kedudukannya berdasarkan skor yang telah diperoleh dimana nilai-nilai tersebut dibandingkan dengan kriteria skor standar, yang diperoleh melalui perhitungan skor ideal (kriterium) dan skor terkecil, sehingga melalui skor standar tersebut dapat diketahui daerah kontinum yang menunjukkan wilayah ideal (Sugiyono 2002:94).

Mencari Skor Ideal Prestasi Belajar

Skor Ideal $=$ Skor Tertinggi $\mathrm{x}$ Jumlah Butir Item x Jumlah responden

Skor Ideal $=5 \times 1 \times 72=360$

Mencari Skor Terendah Prestasi Belajar

Skor Terendah $=$ Skor Terendah $\mathbf{x}$ Jumlah Butir Item x Jumlah responden

Skor Terendah $=1 \times 1 \times 72=72$

Mencari Panjang Interval Kelas Prestasi Belajar

Panjang Interval Kelas $=$ Skor Ideal : Banyak Kelas Interval

Panjang Interval Kelas $=\mathbf{3 6 0}: \mathbf{5}=\mathbf{7 2}$

Berdasarkan penelitian dapat dilihat bahwa pada variabel $\mathrm{Y}$, jumlah skor yang diperoleh sebesar $277 . \quad$ apabila dipersentasikan dengan skor ideal, maka diperoleh persentase sebesar 76,94\% (277 x 360) $\times 100$ termasuk ke dalam daerah kriterium cukup tinggi (sedang).

\section{Pengaruh Metode Cooperative Learning Teknik Jigsaw Terhadap Prestasi Belajar}

Hasil perhitungan analisis data dari variabel metode cooperative learning teknik jigsaw dan prestasi belajar yang telah dilakukan, maka dapat diketahui bahwa metode cooperative learning teknik jigsaw berpengaruh secara positif terhadap prestasi belajar.

Dari hasil penelitian diperoleh angka koefisien korelasi 0,812 antara variabel metode cooperative learning teknik jigsaw (X) dengan variabel prestasi belajar (Y) 
memiliki hubungan yang ternasuk kategori sangat tinggi/kuat. Selain itu, metode cooperative learning teknik jigsaw yang memiliki pengaruh yang positif terhadap prestasi belajar. Hal ini terbukti dengan hasil perhitungan koefisien determinasi yaitu dengan mengkuadratkan koefisien korelasi $\mathrm{r}^{2}$ x $100 \%=(0,812)^{2} \times 100 \%$ diperoleh hasil sebesar 65,9 yang berarti bahwa perubahan variabel prestasi belajar sebesar 65,9 dipengaruhi oleh metode cooperative learning teknik jigsaw sedangkan 34,1 dipengaruhi olah faktor lain $(\varepsilon 1)$.

Adapun untuk mengetahui uji probabilitas atau uji pengambilan keputusan maka dapat diketahui melalui tabel anova atau $\mathrm{F}$ test dimana $\mathrm{F}_{\text {hituag }}$ yaitu sebesar 135.405 dengan tingkat signifikansi sebesar 0,000 dan probabilitas $(0,000)$, sedangkan $\mathrm{F}_{\text {tabel }}=2,35$ karena nilai $\mathrm{F}_{\text {hitung }}>\mathrm{F}_{\text {tabel }}$ maka dapat disimpulkan tolak $\mathrm{H}_{\mathrm{o}}$. Artinya ada hubungan linear antara metode cooperative learning teknik jigsaw dengan prestasi belajar. Hal ini dapat dilihat pada tabel Sig 0,000 yang lebih kecil dari taraf signifikansi 5\%. Maka dapat dikatakan bahwa metode cooperative learning teknik jigsaw berpengaruh terhadap prestasi belajar. Walaupun demikian, jika pada proses uji koefisien regresi, ternyata konstanta dinyatakan tidak valid, maka koefisien regresi (X) adalah valid, sehingga model persamaan regresi tetap dapat dipakai untuk memprediksi prestasi belajar.

Pengambilan keputusan pengujian hipotesis dilakukan dengan membandingkan $t_{\text {hitung }}$ dengan $t_{\text {tabel }}$ perhitungan uji signifikansi dengan menggunakan alpha 0,05 pada uji satu pihak dengan derajat kebebasan (dk) n-2 maka $\mathrm{dk}=70$ diperoleh $\mathrm{t}_{\text {hitua }}$ dan $\mathrm{t}_{\text {tabel }}$ dengan taraf kesalahan 0,05. Berdasarkan ketentuan hipotesis diterima jika $t_{\text {hitua }}>t_{\text {tabel }}$ maka diketahui bahwa harga $t_{\text {hituag }}>t_{\text {tabel }}(11,636>$ 1,700) sehingga dapat disimpulkan bahwa koefisen korelasi antara metode cooperative learning teknik jigsaw dengan prestasi belajar memiliki hubungan yang signifikan.

Pernyataan tersebut diperoleh melalui pengujian hipotesis yang menggunakan metode regresi linier regresi tersebut ditunjukkan dengan perolehan prestasi belajar sebesar 6.425 ditambah 1.361 dari metode cooperative learning teknik jigsaw atau $\mathrm{Y}=(6,425+1,361 \mathrm{X})$ dimana hasil tersebut dapat diartikan, bila nilai setiap penambahan $1 \%$ metode cooperative learning teknik jigsaw akan meningkatkan prestasi belajar yaitu sebesar $1,361 \%$. Hal ini menerangkan bahwa metode cooperative learning teknik jigsaw memiliki kontribusi yang sangat tinggi terhadap prestasi belajar yaitu sebesar 1,361 dimana koefisien determinasi $\left(\mathrm{r}^{2}\right)$ yaitu 0,659 termasuk kategori tinggi (0.600 - 0.799)

Koefisien korelasi yang bernilai positif menunjukkan bahwa hubungan antara kedua variabel tersebut berbanding lurus, artinya jika guru menggunakan metode cooperative learning teknik jigsaw maka dapat diprediksi bahwa prestasi belajar akan naik. Namun, sebaliknya jika guru tidak menggunakan metode cooperative learning teknik jigsaw maka dapat diprediksi bahwa prestasi belajar akan bisa menurun bahkan lebih buruk untuk jangka panjang.

Metode cooperative learning teknik jigsaw yang dilakukan oleh guru akan mempengaruhi prestasi belajar peserta didik.. Hal ini sesuai dengan pernyataan yang dikemukakan oleh Roger dandavid Johnson (1996) mengungkapkan bahwa metode cooperative learning baik untuk digunakan sesuai dengan hasil dari penelitian tentang penggunaan metode cooperative learning antara lain: mendukung pembelajaran siswa dan pencapaian akademik, meningkatkan daya ingat siswa, meningkatkan kepuasan siswa dengan pengalaman belajar mereka, membantu siswa megembangkan kemampuan dalam berkomunikasi secara lisan, mengembangkan kemampuan sosialisasi siswa, meningkatkan kepercayaan diri siswa dan membantu siswa untuk meningkatkan hubungan persaingan yang positif

\section{KESIMPULAN}

Berdasarkan uraian teori, data. pengolahan, dan analisis data serta pembahasan yang telah dijabarkan dan 
dikemukakan sebelumnya maka dapat diambil kesimpulan sebagai berikut:

1 Gambaran metode cooperative learning teknik jigsaw dinilai kuat dan secara berurutan dapat diketahui indikatorindikator yang paling dominan dari indikator lainnya adalah indikator ketepatan yakni ketepatan cooperative learning teknik jigsaw dalam proses belajar mengajar dan indikator tertinggi kedua menurut tanggapan responden yang mendapat skor tertinggi dan yang paling dominan adalah indikator ketepatan guru dalam penerapan metode cooperative learning teknik jigsaw dan yang paling rendah menurut tanggapan responden adalah Penggunaan metode cooperative learning terhadap karakteristik siswa.

2 Hasil belajar yang diperoleh dari program Tata Niaga sudah menggambarkan hasil belajar yang tinggi yaitu 90,35.

Terdapat pengaruh metode cooperative learning teknik jigsaw terhadap prestasi belajar dalam mata kuliah manajemen operasi pada mahasiswa program Tata Niaga angkatan 2006 Jurusan Ekonomi FPIPS UPI UPI termasuk kategori tinggi yakni 0,659 artinya $65,9 \%$ perubahan prestasi belajar disebabkan oleh perubahan metode cooperative learning teknik jigsaw dan $34,1 \%$ dipengaruhi oleh faktor lain $(\varepsilon 1)$

\section{REKOMENDASI}

Berdasarkan uraian kesimpulan diatas sebagai saran untuk meningkatkan dan mempertahankan hasil belajar pada mahasiswa program Tata Niaga angkatan 2003 Jurusan Ekonomi FPIPS UPI melalui metode cooperative learning teknik jigsaw, maka guru mata kuliah SBM perlu melakukan upaya-upaya evaluasi yakni:

1. Berdasarkan hasil penelitian, Penggunaan metode cooperative learning terhadap karakteristik siswa dinilai rendah oleh responden apabila dibandingkan dengan indikator lainnya sehingga perlu diperhatikan oleh pengajar kesiapannya dalam memulai metode cooperative learning yang dimulai dari pembentukan kelompok, karena dalam pembentukan kelompok siswa dikelompokkan berdasarkan perbedaan karakteristik siswa. Guru harus mampu memfasilitasi setiap kelompok melalui pengarahan-pengarahan.

2. Berdasarkan hasil penelitian hasil belajar dalam mata kuliah SBM pada mahasiswa program Tata Niaga angkatan 2003 Jurusan Ekonomi FPIPS UPI sangat baik dan diharapkan hal ini dapat dipertahankan dan mempengaruhi pada matakuliah yang lain

\section{DAFTAR PUSTAKA}

Arikunto, Suharsimi. 2002, Prosedur Penelitian Suatu Pendekatan Praktis, Jakarta Alipandie, : Rineka Cipta

Imansjah. 1984, Didaktik Metode Pendidikan Umum, Surabaya: Usaha Nasional

Hamalik, Oemar. 1995. Media Pendidikan, Bandung: Alumni Pendidikan

Kusmana, E. 1989, Proses Belajar Mengajar: Asas Strategi Metode, Bandung: jurusan Pendidikan Dunia Usaha, FPIPS, IKIP Bansung

Kemp, Jerold. 1994, Proses Perancangan Pengajaran, Bandung: Remaja Rosdakarya

Lie, Anita. 2004, Cooperative Learning, Jakarta: Grasindo

Poewadarminta, 1982, Kamus Umum Bahasa Indonesia, Jakarta: Balai Pustaka

Rusyan, Tabrani, dkk. 1994, Interaksi dan Motivasi Belajar Mengajar, Jakarta: Rajawali Pers

Sudjana, 2000, Metode Statistik, Bandung: Tarsito

Sudjana, Nana. 1989,Dasar-Dasar Proses belajar Mengajar, Bandung: Sinar Baru

Sugiyono, 2001, Metode Penelitian Bisnis, Bandung: Alfabeta. 2002, Metode Penelitian Bisnis, Bandung: Alfabeta. , 2005, Statistika Untuk Penelitian, Bandung: Alfabeta. ,2006, Metode Penelitian Bisnis, Bandung: Alfabeta.

Syamsudin, Abin. 2001, Psikologi Kependidikan, Bandung: Rosda

S, Nasution. 1982, Teknologi Pendidikan, Bandung: Jenmars

Umar, Husein. (2002), Metode Riset Bisnis, Jakarta: PT. Gramedia Pustaka Utama.

Winarto Surakhmad, 1990, Metodologi Pengajaran Nasional,Bandung: Jemmar 